\title{
The cross on rings performed by an Olympic champion
}

CDD. 20.ed. 796.023

796.41

http://dx.doi.org/10.1590/1807-55092016000100071

\author{
Paulo CARRARA* \\ Alberto Carlos AMADIO** \\ Júlio Cerca SERRÃO** \\ Gareth IRWIN*** \\ Luis MOCHIZUKI ${ }^{* * * * *}$
}

*Centro Universitário das Faculdades Metropolitanas Unidas São Paulo, SP, Brasil. ${ }^{* *}$ Escola de Educação Física e Esporte, Universidade de São Paulo, São Paulo, SP, Brasil.

${ }^{* * *}$ Cardiff School of Sport, Cardiff Metropolitan University, Cardiff, Wales, United Kingdon ****Escola de Artes Ciências e Humanidades, Universidade de São Paulo, São Paulo, SP, Brasil.

the cross is a key skill in Male Artistic Gymnastics rings routines. However, few researches were found about the cross, or about muscles activation, separately. The aim of this paper was to accomplish a comprehensive research about the biomechanics of cross on rings, in order to obtain a descriptive model about this skill. Therefore, the currently Olympic champion on rings event volunteered in this research. He performed three crosses with the usual apparatus in his training gym. The measurement methods were combined: One digital video camera, one strain gauge in each cable and surface electromyography of nine right shoulder muscles were used. Statistical analyses were performed by parametric and non parametric tests and descriptive statistics. Symmetry values were calculated for shoulder angles and cables of right and left side. Coefficient of variation of muscle activation and co contraction were verified. Within gymnast variability was calculated using biological coefficient of variation (BCV), discretely for kinematic measures. Low variability values of shoulder angles and cable forces were verified and low values of asymmetry as well. Muscle activation varied according to muscle function, while co-contraction values were different among trials. These results pointed out the characteristics of the cross performed by an elite gymnast. Knowledge about the characteristics of cross can inform coaches, practitioners and clinicians how a successful skill should be presented.

KeY Words: Artistic gymnastics; Biomechanics; Performance.

\section{Introduction}

The cross is a key skill on rings, which is one event of male artistic gymnastics. It is characterised by maintaining $90^{\circ}$ shoulder abduction in the frontal plane with both limbs for at least two seconds, while the elbows are extended ${ }^{1}$. Moreover, penalties are applicable if a gymnast fails to hold the posture over two seconds or with shoulder angles below $90^{\circ}{ }^{1}$. The cross requires from gymnast to hold his shoulder in an anatomical position that involves the extension of passive structures of the glenohumeral joint, causing shoulder instability ${ }^{2-3}$.

Studies of gymnastics rings rely mainly on handstand $d^{4-5}$. Recently, strength skills were studied $^{6-7}$, but no information was provided about muscles cocontraction in the cross ${ }^{6}$.

Considering the kinetics of cross, force plates were used to measure the combined forces which were necessary to the gymnast to perform the cross $^{8}$. The summed forces should be equivalent or higher as the gymnasts' bodyweight to perform the skills. The time series data showed differences between limbs; but, none focused about the asymmetry differences. There were no papers found regarding the kinematics of this skill.

It is necessary to consider a set of measurements, such as force-instrumented rings $s^{4}$, for a comprehensive understanding of a skill ${ }^{9}$. Nonetheless, more knowledge is required about the relation of muscles activity, kinematics and kinetics of cross performed on training or competitions rings, restraining a full understanding of the skill and the drill, and properly compare them biomechanically.

The first medal for a Latin American gymnast was achieved by a Brazilian on rings event, in 2012 
summer Olympic Games. Such success reveals the quality of the skills performed by the gymnast, being a top case for study. This research approaches

\section{Method}

\section{Participant}

The Brazilian gymnast (24 years old, $1.56 \mathrm{~m}$ height, $61.9 \mathrm{~kg}$ mass, 17 years of practice) who volunteered to join the study is Olympic champion (2012) and World Championship medallist (2011, 2013 and 2014). He was informed about the study protocol and signed an informed consent, approved by University of São Paulo Ethics and Research Committee - CEP 717.171.

\section{Instruments}

One digital camera (model Logitech HD - $50 \mathrm{~Hz}$ ) was placed five meters away at rings height and facing the frontal plane. The camera was connected via USB to a computer and video recording was controlled with the software MyoResearch (version 3.2, Noraxon, USA). The camera and electromyography (EMG) channels were connected to a data acquisition system controlled by Myoresearch (Noraxon) software for acquisition, synchronizing, analogical/ digital conversion of data and storage.

The calibration frame comprised of six markers made of $20 \mathrm{~mm}$ wide reflexive tape, fixed directly onto the rings frame, forming rectangular solids of three meters high by three meters wide ${ }^{4}$. Reflexive markers were placed based in anatomical landmarks according to upper limbs model ${ }^{10-11}$ following the International Society of Biomechanics recommendations ${ }^{11}$. Only the anterior view was evaluated for digitalization. The raw position data was processed and data input into the software Visual 3D (version 5, C-Motion).

A 12 channels EMG system (Myosystem 1400, Noraxon, Inc USA) was used to record the electrical activity of nine muscles of right upper arm, shoulder and trunk (mm. pectoralis major, PE; latissimus dorsi, LT; teres major, TM; infraspinatus, IE; trapezius - pars descendents, TZ; medial deltoid, MD; biceps brachii - caput longum, BI; triceps brachii - caput longum, TB; serratus, ST) at $1500 \mathrm{~Hz}$ sampling frequency.

For the kinetics, a one dimension strain gauge (EMG system Brazil model 2t) was attached to beginning of each cable ring to measure the cable tension during the task ${ }^{4}$. The longitudinal cable a comprehensive use of biomechanical variables, describing the skill and quantifying the variability of an elite level gymnast performing the cross on rings.

forces of two strain gauges were connected to an analogical/digital converter (EMG system Brazil model 1610). A trigger (EMG system Brazil) was used to synchronize video and force signals.

The EMG signal was measured with bipolarsurface-differential-active electrodes. The sites for electrode placement were prepared by abrading the skin with fine sandpaper and cleaning with alcohol. Shaving was performed if necessary. The distance between the centres of the disposable electrodes was two centimetres. The placing of electrodes followed the procedures indicated by SENIAN ${ }^{12}$ and for muscles not indicated by SENIAN, the electrodes was placed onto the medial line of muscle belly ${ }^{13}$.

\section{Task procedure}

The gymnast has done his warm up exercises, similar to what he usually does before a training section on rings. He performed the cross three times on competition rings ${ }^{13}$. The initial position was when the participant has reached the maintenance position with upper limbs abducted with $90^{\circ}$ to the trunk on the transverse plane. The participant has maintained the cross posture for two seconds; then, an oral warning was used to stop the cross. The attempts were considered valid by one gymnastics judge accredited by Fédération Internationale de Gymnastique. Between each repetition, the participant had two minutes to rest. Data collection took place at the gymnast's training gym, with the apparatus he uses to train for competitions.

\section{Sinal processing}

Videos were digitised and data were filtered with a low-pass Butterworth filter, with appropriate cutoff frequency determined by residual analysis ${ }^{14}$. Digitised data of the calibration markers was combined with their known locations to calibrate the camera digitiser system, using the direct linear transformation (DLT) procedure ${ }^{15}$. The known locations of the digitised landmarks on the gymnast and rings apparatus were subsequently reconstructed using the calibrated camera digitiser system based 
on DLT procedure ${ }^{15}$ using Matlab 6.5 (Mathworks Inc) ${ }^{16}$. For those digitizing and reconstruction, a specific routine "DV5" was run in Matlab".

Image digitalization occurred in Matlab; then, the coordinate data was converted in file converter (C-Motion) and exported into Visual 3D software for calculation of shoulder angle. An upper limbs model ${ }^{10}$ was applied to the data points, and the angle between trunk and arm was considered as shoulder angle. Data was related to the gymnast reaching the static posture and the following two seconds of duration.

EMG was normalized by the peak value within the trials. Raw EMG signals was demeaned, rectified and filtered with a low-pass Butterworth filter of 4th order of $200 \mathrm{~Hz}$. Kinematics, kinetics and EMG data were interpolated to $500 \mathrm{~Hz}$.

\section{Data analysis}

Symmetry left/right for angles and forces index were evaluated by means of symmetry indexes. Percentage difference for cable FSYM values were calculated using symmetry index method ${ }^{17}$ (Equation 1):

$F_{\text {SYM }}=\frac{F_{\text {Rcable }}-F_{\text {Lcable }}}{F_{\text {Rcable }}} .100$

Equation 1

Where FR and FL are the right and left forces, respectively.

Percentage differences between left and right angle values were calculated using the symmetry angle index $\left(\theta_{\text {SYM }}\right)$ method $^{17}$ (Equation 2):

$\theta_{\text {SYM }}=\frac{45^{\circ}-\arctan \left(\frac{\theta_{\text {left }}}{\theta_{\text {right }}}\right)}{90^{\circ}} .100$

Equation 2
Where $\theta_{\text {SYM }}$ is the symmetry angle; $\theta_{\text {left }}$ is the gymnast's mean left shoulder angle and $\theta_{\text {right }}$ is the gymnast's mean right shoulder angle. Symmetry angles were rectified, allowing the magnitude of those values to be more easily compared between conditions.

EMG time series were compared by means of cross correlation in order to calculate the correlation index $\mathrm{R}$. Cocontraction index is $\mathrm{R}^{2}$ for lag zero. Cross correlation analysis was performed between all possible muscle pairs. Muscle pairs were grouped according to their function. The agonists (PE, LD, TM and TR), antagonist (DE) and postural (SE, BI, TZ and IF) muscles were grouped into functional groups. The dependent variables were the kinematics, kinetics and EMG variables. The independent variables were side (two levels: left and right sides), and function groups (five levels: agonist/ antagonist, agonist/agonist, agonist/postural, antagonist/postural and postural/postural).

\section{Statistical analysis}

Gymnast trial means (M), standard deviations (SD), coefficients of variation (CV\%), standard errors of the mean (SEM\%), and biological coefficients of variation (BCV\% = CV\% - SEM\%) were calculated ${ }^{18}$ for kinematics and kinetics values $^{19-20}$. Where the BCV value was less than $10 \%$, the variable was considered to have low variability ${ }^{18}$. The co-contraction index was compared across by means of analysis of variance. Normality tests for the data set were confirmed only for kinematics, by using the Sigmastat Software (version 3.5).

\section{Results}

Mean shoulder angles during cross are shown on TABLE 1. Right and left shoulder angles, coefficient of variation (\%), asymmetry, standard errors of the mean (\%) and biological coefficient of variation (\%) values are depicted. Coefficient of variation was lower than $5 \%$, while biological coefficient of variation was lower than $1 \%$.

Mean results of right and left cable forces, coefficient of variation and asymmetry index are showed on
TABLE 2. Coefficient of variation was lower than 5\%, while Force asymmetry was lower than $10 \%$.

The average electrical activity of upper limbs muscles during the performance of cross at competition rings are presented on TABLE 3. Cocontraction indexes were calculated for all muscle pairs. Those pairs were separated by their functional status agonist, antagonist and postural. Functional relation affected cocontraction $\left(\mathrm{F}_{5,215}=2.3 \mathrm{p}=0.04\right)$. 
TABLE 1 - Gymnasts' shoulder angle mean, SD, CV, asymmetry $\left(\theta_{\mathrm{SYM}}\right)$, SEM and BCV on cross.

BCV $<10 \%:$ Iow variability.

\begin{tabular}{lccccc}
\hline \multirow{2}{*}{ Trial } & \multicolumn{2}{c}{ Right Shoulder } & \multicolumn{2}{c}{ Left Shoulder } & \multirow{2}{*}{$\theta_{\text {SYM }}$} \\
\cline { 2 - 5 } & $\theta\left(^{\circ}\right)$ & CV & $\theta\left(^{\circ}\right)$ & CV & 0.72 \\
\hline 1 & $84.5 \pm 1.81$ & 0.02 & $82.6 \pm 0.63$ & 0.02 & 0.91 \\
2 & $85.5 \pm 1.07$ & 0.01 & $83.1 \pm 1.29$ & 0.01 & 0.57 \\
3 & $84.6 \pm 1.68$ & 0.02 & $83.1 \pm 1.54$ & 0.02 & 0.73 \\
Mean & $84.8 \pm 1.38$ & 0.02 & $82.9 \pm 1.15$ & 0.01 & - \\
SEM & 0.32 & - & 0.17 & - & - \\
BCV & 0.30 & - & 0.16 & - & \\
\hline
\end{tabular}

TABLE 2 - Cable forces $(\mathrm{N})$ mean and SD, CV and asymmetry $\left(\mathrm{F}_{\mathrm{SYM}}\right)$ values (\%) on cross.

\begin{tabular}{lccccc}
\hline \multirow{2}{*}{ Trial } & \multicolumn{2}{c}{ Right Cable } & \multicolumn{2}{c}{ Left Cable } & \multirow{2}{*}{ F $_{\text {SYM }}(\%)$} \\
\cline { 2 - 5 } & $\mathbf{F ~ ( N )}$ & $\mathbf{C V}$ & $\mathbf{F ~}(\mathbf{N})$ & $\mathbf{C V}$ & \\
\hline 1 & $354 \pm 3.54$ & 0.01 & $328 \pm 4.95$ & 0.02 & 7.34 \\
2 & $358 \pm 2.12$ & 0.01 & $325 \pm 3.54$ & 0.01 & 9.22 \\
3 & $356 \pm 3.54$ & 0.01 & $324 \pm 3.54$ & 0.01 & 8.15 \\
Mean & $356 \pm 1.63$ & 0.01 & $326 \pm 1.83$ & 0.01 & 8.43 \\
\hline
\end{tabular}

TABLE 3 - EMG normalized, mean, SD and CV (\%) on cross.

\begin{tabular}{lccccccccc}
\hline \multirow{2}{*}{ Trial } & \multicolumn{8}{c}{ Muscle } \\
\cline { 2 - 10 } & PE & ST & BI & TP & MD & TZ & IE & TM & LT \\
\hline 1 & 0.89 & 0.99 & 1.03 & 0.96 & 1.02 & 1.02 & 1.16 & 1.11 & 0.95 \\
2 & 0.92 & 0.97 & 0.96 & 1.03 & 1.00 & 1.01 & 0.99 & 0.96 & 1.08 \\
3 & 1.19 & 1.05 & 1.01 & 1.00 & 0.97 & 0.97 & 0.85 & 0.93 & 0.98 \\
mean & 1.00 & 1.00 & 1.00 & 1.00 & 1.00 & 1.00 & 1.00 & 1.00 & 1.00 \\
SD & 0.16 & 0.04 & 0.04 & 0.03 & 0.03 & 0.03 & 0.15 & 0.10 & 0.07 \\
CV (\%) & 0.16 & 0.04 & 0.04 & 0.03 & 0.03 & 0.03 & 0.15 & 0.10 & 0.07 \\
\hline
\end{tabular}

\section{Discussion}

The gymnast performed the cross with shoulder angle deviations from $90^{\circ}$, which could lead to penalties on competition presentation ${ }^{1}$. This finding may be due to the model that considered the angle between trunk and upper $\operatorname{arm}^{10}$. For judging criteria, the set of forearm and upper arm is considered for accounting shoulder angle. Kinematics measurement provides useful information for coaching gymnastics skills, which may subjectively appear to be symmetrical ${ }^{21}$. The variation obtained in static position may occur due to gymnast and rings cables interaction. As the gymnast started from support position, lowering to reach the static position of cross, the action of shoulders abduction may cause the rings swinging, leading to the variations on the shoulder angles measured.

Knowledge of shoulder asymmetry can facilitate the understanding and the development of this gymnastic skill ${ }^{22}$, improving performance and developing more complex skill combinations safely and effectively, ${ }^{9}$. During the static cross position, asymmetry directly influences performance, due to penalties for asymmetrical posture and shoulder angle deviating from $90^{\circ}$. 
The experienced gymnast in this study showed reduced biological coefficient variability for shoulder angle. These could be explained from the performance perspective, due to the fact that this action of abduction is biomechanical key aspect for successful technique performance ${ }^{1,19}$. This is in accordance with the findings reported by HiLEY et al..$^{24}$ who showed that in elite gymnasts there was lower variability in the mechanically important aspects of gymnastic performance.

It is possible to observe that, such as angles values, the forces values were not symmetric. However, force asymmetry scores below $10 \%$, as found in the present study, are considered low ${ }^{25}$. Low variability on forces means that a controlled skill is performed ${ }^{26}$. Because the cross is a closed skill, well learned and performed by experts, it is reasonable to assume a stable movement pattern would exist ${ }^{27}$. Asymmetry scores were used to analyse performance in sprint running ${ }^{28}$ and to allow for asymmetry comparisons between athletes over time and between asymmetry and performance ${ }^{21}$. In gymnastics, particularly on rings, force asymmetry has direct implications on performance as penalties can be applied for cables swinging ${ }^{1}$.

Muscle activation over trials was not studied in other studies about cross ${ }^{6}$. The coefficient of variation was higher for Pectoralis and Teres Major (agonists) and Infraspinal (postural) muscles. The interaction between anterior and posterior agonists variation was necessary for the maintenance of the position ${ }^{3}$. The cross lasted four seconds, from support until the end of static maintenance, and no indices of skill failure ${ }^{20}$ during task repetition were observed, as shoulder angles $\mathrm{CV}$ were below $5 \%$. However, co-contraction values were different $\left(\mathrm{F}_{5,215}=2.3 \mathrm{p}=0.04\right)$ among trials, showing that the gymnast employed different motor strategies to achieve the same motor task ${ }^{20,29}$. Cocontraction variation may be a strategy used by the motor system to facilitate multi-joint arm skill accuracy ${ }^{30}$. Moreover, any rings swing forward/backward could be present, in a different way among trials, due to the unstable apparatus characteristics of construction ${ }^{4}$, influencing on muscles activation. Furthermore, there are evidences for altered muscle activation associated with shoulder impingement, rotator cuff tendinopathy, rotator cuff tears, glenohumeral instability, adhesive capsulitis, and stiff shoulders ${ }^{31}$.

Besides gymnasts had been questioned about their shoulder conditions and the ability to perform the cross, any of these shoulder clinical conditions could be presented in the participant, and had influenced on obtained results. Gymnasts performing without clinical evaluation can be a common practice, as they still able to perform even feeling discomfort ${ }^{32}$ and shoulder is the most commonly injured joint in men's gymnastics, 33 .

This paper brings a high ecological validity about the cross on rings skill, performed by the currently Olympic champion, on his usual apparatus and training gym. The skills were considered similar, with low variability over the measurements, showing the characteristics of performance of elite level on this skill. Values observed for angles and forces symmetry within the skill should be considered as important source of information for coaches, as individual characteristics of performance variation of the cross on rings. Muscular activity suggests that the elite level gymnast enclose different motor strategies to perform the skill. It should be emphasised that coaches need to consider individual capacities when comparing the results depicted here with those found within another gymnasts.

\section{Resumo}

\section{0 crucifixo nas argolas executado por um campeão olímpico}

0 crucifixo é uma habilidade essencial na prova das argolas na Ginástica Artística Masculina. Entretanto, poucas pesquisas foram encontradas sobre esta habilidade. Há conhecimento sobre as forças necessárias para a realização do crucifixo, ou sobre a ativação muscular, isoladamente. 0 objetivo deste artigo foi realizar uma pesquisa abrangente sobre a biomecânica do crucifixo nas argolas, de forma e obter um modelo descritivo desta habilidade. Para isto, o atual campeão olímpico na prova de argolas foi voluntário desta pesquisa. Ele realizou três crucifixos em seu ginásio e com os aparelhos habituais. Foram combinados os métodos de mensuração: uma câmera de vídeo digital, uma célula de carga acoplada em cada cabo das argolas e eletromiografia de superfície em nove músculos do ombro direito. Os resultados foram comparados por testes paramétricos, não paramétricos e estatística descritiva. Valores de simetria foram calculados 
para os ângulos dos ombros e forças nos cabos direito e esquerdo. Coeficientes de variação de ativação muscular e cocontração também foram verificados. A variabilidade entre as tentativas foi calculada com a utilização do coeficiente biológico de variação (BCV), para as medidas discretas de cinemática. São descritos os ângulos dos ombros e forças nos cabos direito e esquerdo, como também a ativação muscular. Houve pequena variância entre as tentativas nos valores de cinemática e dinâmica, como também nos valores de simetria. A ativação muscular variou conforme a função muscular, enquanto os valores de cocontração foram diferentes entre as tentativas. Estes resultados distinguem as características do crucifixo realizado por um ginasta de nível elite. 0 conhecimento sobre as caracteristicas do crucifixo podem informar técnicos, ginastas e profissionais da área da saúde sobre como esta habilidade deve ser apresentada em alto nível.

Palavras-chave: Ginástica artística; Biomecânica; Performance.

\section{References}

1. Fédération Internationale de Gymnastique. 2013-2016 Code of Points: men's artistic gymnastics. Lausanne: FIG; 2015.

2. Graichen H, Hinterwimmer S, Eisenhart-Rothe RY, Vogl T, Englmeier KH, Eckstein F. Effect of abducting and adducting muscle acitivity on glenohumeral translation, scapular kinematics and subacromial space width in vivo. J Biomech. 2005;38:755-60.

3. Levangie PK, Norkin CC. Joint structure \& function: a comprehensive analysis. 4th ed. Philadelphia: F.A. Davis; 2005.

4. Brewin MA, Yeadon MR, Kerwin DG. Minimising peak forces at the shoulders during backward longswings on rings. Hum Mov Sci. 2000;19:717-36.

5. Nassar L, Sands W. The artistic gymnast's shoulder. In: Wilk KE, Reinold MM, Andrews JR, editors. The athlete's shoulder. New York: Elsevier; 2009. p.491-506.

6. Bernasconi S, Tordi N, Parratte B, Rouillon J-D, Monnier G. Surface electromyography of nine shoulder muscles in two iron cross conditions in gymnastics. J Sports Med Phys Fitness. 2004;44:240-5.

7. Bernasconi SM, Tordi NR, Parratte BM, Rouillon JDR, Monnier GG. Effects of two devices on the surface electromyography responses of eleven shoulder muscles during Azarian in gymnastics. J Strength Cond Res. 2006;20:53-7.

8. Dunlavy JK, Sands WA, McNeal JR, et al. Strength performance assessment in a simulated men's gymnastics still rings cross. J Sports Sci Med. 2007;6:93-7.

9. Irwin G, Bezodis IN, Kerwin DG. Biomechanics for coaches. In: Jones R, Kingston K, editors. An introduction to sports coaching: connecting theory to practice. London: Routledge; 2013. p.145-60.

10. Rab G, Petuskey K, Bagley A. A method for determination of upper extremity kinematics. Gait Posture. 2002;15:113-9.

11. Wu G, van der Helm FCT, Veeger HEJ, et al. ISB recommendation on definitions of joint coordinate systems of various joints for the reporting of human joint motion. Part II: shoulder, elbow, wrist and hand. J Biomech. 2005;38:981-92.

12. Hermens HJ, Freriks B, Disselhorst-Klug C, Rau G. Development of recommendation for SEMG sensors and sensors placement procedures. J Electromyogr Kinesiol. 2000;10:361-74.

13. De Luca C. The use of surface electromyography in biomechanics. J Appl Biomech. 1997;13:135-63.

14. Winter DA. Biomechanics and motor control of human movement. Hoboken: John Wiley; 2009.

15. Abdel-Aziz Y, Karara H. Direct linear transformation from comparator coordinates into object space coordinates in close-range photogrammetry. Symposium on Close-Range Photogrammetry; 1971; Falls Church, VA. Fall Church: American Society of Photogrammetry; 1971. p.1-18.

16. Hedrick TL. Software techniques for two- and three-dimensional kinematic measurements of biological and biomimetic systems. Bioinspir Biomim. 2008;3:034001.

17. Zifchock RA, Davis I, Higginson J, Royer T. The symmetry angle: a novel robust method of quantifying asymmetry. Gait Posture. 2008;27:622-7.

18. Bradshaw EJ, Maulder PS, Keogh JWL. Biological movement variability during the sprint start: performance enhancement or hindrance? Sports Biomech. 2007;6:246-60.

19. Farana R, Irwin G, Jandacka D, Uchytil J, Mullineaux DR. Elbow joint variability for different hand positions of the round off in gymnastics. Hum Mov Sci. 2015;39:88-100.

20. Preatoni E, Hamill J, Harrison AJ, et al. Movement variability and skills monitoring in sports. Sports Biomech. 2013;12:69-92.

76 • Rev Bras Educ Fís Esporte, (São Paulo) 2016 Jan-Mar; 30(1):71-77 
21. Exell TA, Gittoes MJR, Irwin G, Kerwin DG. Considerations of force plate transitions on centre of pressure calculation for maximal velocity sprint running. Sports Biomech. 2012;11:532-41.

22. Exell TA, G. I, Godden S, Kerwin DG. Asymmetry analysis of the arm segments during forward handspring on floor. In: Bradshaw E, Burnett A, Hume P, editors. XXXth International Symposium on Biomechanics in Sports. Melbourne: Australian Catholic University; 2012. p.182-5.

23. Readhead L. Men's gymnastics coaching manual. Marlborough: Crowood; 1997.

24. Hiley MJ, Zuevsky VV, Yeadon MR. Is skilled technique characterized by high or low variability? An analysis of high bar giant circles. Hum Mov Sci. 2013;32:171-80.

25. Zifchock RA, Davis I, Higginson J, McCaw S, Royer T. Side-to-side differences in overuse running injury susceptibility: a retrospective study. Hum Mov Sci. 2008;27:888-902.

26. Williams G, Irwin G, Kerwin DG, Newell KM. Kinematic changes during learning the longswing on high bar. Sports Biomech. 2011;11:20-33.

27. Hiley MJ, Yeadon MR. Investigating optimal technique in a noisy environment: application to the upstart on uneven bars. Hum Mov Sci. 2013;32:181-91.

28. Exell TA, Irwin G, Gittoes MJR, Kerwin DG. Implications of intra-limb variability on asymmetry analyses. J Sports Sci. 2012;30:403-9.

29. Irwin G, Kerwin DG. Inter-segmental coordination in progressions for the longswing on high bar. Sports Biomech. 2007;6:131-44.

30. Gribble PL, Mullin LI, Cothros N, Mattar A. Role of cocontraction in arm movement accuracy. J Neurophysiol. 2003;89:2396-405.

31. Ludewig PM, Reynolds JF. The association of scapular kinematics and glenohumeral joint pathologies. J Orthop Sports Phys Ther. 2009;39:90-104.

32. Caraffa A, Cerulli G, Rizzo A, Buompadre V, Appoggetti S, Fortuna M. An arthroscopic and electromyographic study of painful shoulders in elite gymnasts. Knee Surg Sports Traumatol Arthrosc. 1996;4:39-42.

33. Caine D, Nassar L. Gymnastics injuries. In: Caine DJ MN, editor. Epidemiology of pediatric sports injuries: individual sports. Basel: Karger; 2005. p.18-58.

\section{Acknowledgment}

Robson Cassefo from APAMED.

Gymnasts and coaches from Agith - São Caetano do Sul - Marcos Goto, Hugo Lopes, Rodrigo Canon.

Supported by CNPq / CAPES - Science Without Borders grant number 249500/2013-2.

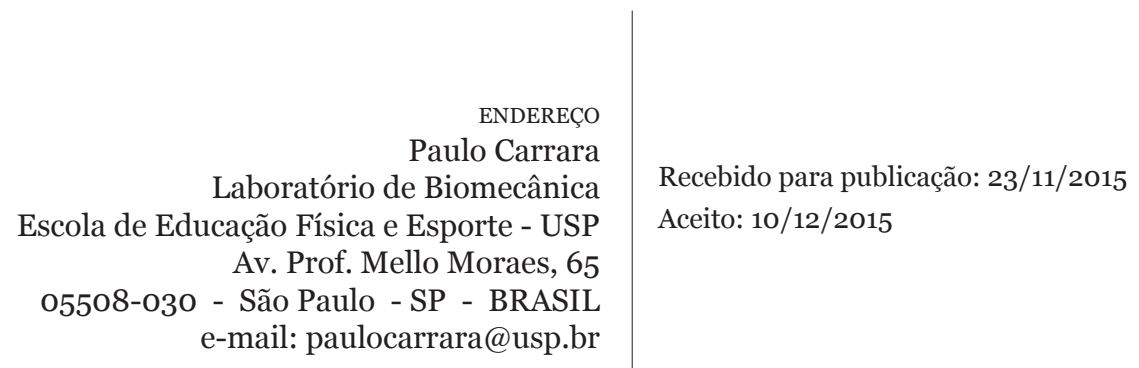

Rev Bras Educ Fís Esporte, (São Paulo) 2016 Jan-Mar; 30(1):71-77 • 77 